\title{
Anti-inflammatory effects of rosuvastatin treatment on coronary artery ectasia patients of different age groups
}

\author{
Cheng-Hui Fan ${ }^{1 \dagger}$, Ying Hao ${ }^{1 \dagger}$, Yong-Hua Liu², Xiao-Lin Li ${ }^{3}$, Zhen-Hao Huang ${ }^{1}$, Yu Luo ${ }^{1 *}$ (D) and Rui-Lin Li ${ }^{1 *}$
}

\begin{abstract}
Background: Coronary artery ectasia (CAE) is an angiographic finding of abnormal coronary dilatation. Inflammation plays a major role in all phases of atherosclerosis. We investigated the relationship between CAE and serum high-sensitivity C-reactive protein (hs-CRP) and interleukin-6 (IL-6) levels to test our hypothesis that patient age is associated with the efficacy of anti-inflammatory therapy for CAE.
\end{abstract}

Methods: We conducted a prospective analysis of 217 patients with CAE treated at the Department of Cardiology, Shanghai East Hospital, Ji'an Campus and the Baoshan People's Hospital, from January 1, 2015 to July 30, 2019. Baseline data of patients, including sex; age; and history of hypertension, hyperlipidemia, and diabetes, were collected from patient medical records. Study participants were grouped by age as follows: CAE-A ( $n=60$, age $\leq 50$ years), CAE-B ( $n=83,50$ years <age $\leq 70$ years), and CAE-C ( $n=74$, age $>70)$. Additionally, there was a control (NC) group $(n=73)$ with normal coronary arteries.

Results: All patients received oral rosuvastatin therapy (10 mg, QN quaque nocte) when they were diagnosed with CAE and maintained good follow-up, with a loss rate of $0.0 \%$ at the end of the 6-month follow-up. The NC group received regular symptom-relieving treatments and rosuvastatin therapy. Of these four groups, the inflammatory markers, hs-CRP and IL-6, were significantly higher in patients with CAE than in the NCs $(p<0.05)$. Post-hoc tests showed that hs-CRP and II-6 levels had significant differences between the CAE-A and CAE-C groups $(P=0.048, P=$ 0.025). Logistic regression analysis showed that hs-CRP $(\mathrm{OR}=1.782,95 \% \mathrm{Cl}: 1.124-2.014, P=0.021)$ and IL-6 $(\mathrm{OR}=$ $1.584,95 \% \mathrm{Cl}: 1.112-1.986, P=0.030$ ) were independent predictors of CAE. The inflammatory markers were higher in the CAE-A group than in the CAE-B group and higher in the CAE-B group than in the CAE-C group. Follow-up after 6 months of rosuvastatin therapy showed a significantly greater reduction in hs-CRP and IL-6 levels in the CAEA group than in the CAE-B group, which again were greater in the CAE-B group than in the CAE-C group.

Conclusions: Anti-inflammatory therapy using rosuvastatin was more effective in younger CAE patients, indicating the need for early statin therapy in CAE.

Keywords: Coronary artery ectasia, High-sensitivity C-reactive protein, Interleukin-6, Rosuvastatin

\footnotetext{
*Correspondence: luoyu201909@163.com; liruilin1234@sina.com

${ }^{+}$Cheng-Hui Fan and Ying Hao contributed equally to this work.

'Department of Cardiology, Shanghai East Hospital, Tongji University, 1800

Yuntai Rd, Shanghai 200126, People's Republic of China

Full list of author information is available at the end of the article
}

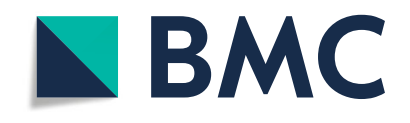

(c) The Author(s). 2020 Open Access This article is licensed under a Creative Commons Attribution 4.0 International License, which permits use, sharing, adaptation, distribution and reproduction in any medium or format, as long as you give appropriate credit to the original author(s) and the source, provide a link to the Creative Commons licence, and indicate if changes were made. The images or other third party material in this article are included in the article's Creative Commons licence, unless indicated otherwise in a credit line to the material. If material is not included in the article's Creative Commons licence and your intended use is not permitted by statutory regulation or exceeds the permitted use, you will need to obtain permission directly from the copyright holder. To view a copy of this licence, visit http://creativecommons.org/licenses/by/4.0/. The Creative Commons Public Domain Dedication waiver (http://creativecommons.org/publicdomain/zero/1.0/) applies to the data made available in this article, unless otherwise stated in a credit line to the data. 


\section{Background}

Coronary angiography, a technique for diagnosing CAE, provides information on the size, location, and number of dilatations. CAE is characteristically defined as a dilated coronary artery segment whose diameter is at least 1.5 times that of the adjacent normal coronary lumen [1]. It is a relatively rare coronary artery abnormality (prevalence $<5 \%$ ) among coronary artery diseases [2]. The increased prevalence of CAE in recent years has resulted in a greater focus on the incidence and factors influencing CAE; estimates of the prevalence of CAE have varied from 0.3 to $4.7 \%$ [3]. Nevertheless, etiopathogenetic mechanism of CAE is not yet completely known, although it may be related to systemic inflammation, stimulated nitric oxide production, coronary balloon angioplasty, extracellular matrix degradation, dyslipidemia, nodular polyarteritis, Kawasaki syndrome, and even genetic predisposition $[4,5]$. CAE is more prevalent in patients with familial hypercholesterolemia (FH) than in those with coronary atherosclerosis and shows a strong inverse association with high-density lipoprotein cholesterol (HDL) cholesterol levels. This suggests that abnormal lipoprotein metabolism in individuals with $\mathrm{FH}$ predisposes patients to aneurysmal coronary artery disease [6]. Moreover, potential risk factors for CAE include an imbalance between matrix metalloproteinases (MMPs) and tissue inhibitor metalloproteinases (TIMPs), angiotensin-converting enzyme genotypes, a lower HDL cholesterol level, a higher low-density lipoprotein (LDL)/HDL ratio, elevated homocysteine levels, cocaine usage, smoking, vascular trauma, and diabetes [7-10]. Conventionally, CAE has been considered a variant of coronary atherosclerosis and an important clinical complication in interventional cardiology with increased thrombogenic potential of the ectatic arteries. CAE is closely related to myocardial infarction. However, there are currently no standard treatment guidelines specified for CAE. Anti-inflammatory and endothelium-protective effects of rosuvastatin have been suggested to improve the symptoms in patients with coronary artery disease [11]. Rosuvastatin is a selective hydroxy methylglutaryl coenzyme A (HMG-CoA) reductase inhibitor widely used for coronary atherosclerotic heart disease [12]. The liver is the main target organ of rosuvastatin, wherein it lowers cholesterol levels and increases the number of LDL receptors on the surface of liver cells, thereby improving lipid metabolism by promoting LDL absorption and inhibiting hepatic synthesis of very-low-density lipoprotein (VLDL) [13]. Statin therapy can exert pleiotropic effects in atherosclerotic processes, such as regulating inflammatory responses, endothelial function, and thrombus formation based on the reduction in LDL-C levels [14]. Rosuvastatin can also stabilize or reverse atherosclerotic plaques by suppressing MMP expression and protecting the vascular endothelium against inflammation $[15,16]$. However, there is no conclusive evidence of therapeutic efficacy or optimal timepoint for rosuvastatin therapy in CAE patients in different age groups. We conducted this study to compare the inflammatory status and therapeutic effects of rosuvastatin in CAE patients in different age groups.

\section{Methods \\ Study population}

We prospectively enrolled 6542 patients who were first diagnosed using coronary angiography at our centers from January 1, 2015, to July 30, 2019. The exclusion criteria included various malignant tumors, intolerance to statin treatment, dilated segments appearing within or directly associated with coronary bypass grafts, coronary dilation development after coronary interventions, a diagnosis of Kawasaki disease, previous statin treatment, or coronary artery anomalies, acute or chronic coronary total occlusion, acute coronary syndrome [17], or inability to complete a 6-month follow-up. Finally, 302 patients were diagnosed with CAE, and 85 patients were excluded (Fig. 1). We also included 73 normal controls. Of the excluded patients, there were 21 patients with congestive heart failure, 26 with abnormal hepatic or renal function, and 38 who met other exclusion criteria. We followed up a total of 290 patients and divided them into four groups: normal control (NC; $n=73)$, CAE-A $(n=60)$, CAE-B $(n=83)$, and CAE-C $(n=74)$ (Fig. 1$)$. Samples were collected for clinical data, including blood lipids, high-sensitivity C-reactive protein (hs-CRP), interleukin-6 (IL-6) and other biochemical indicators (Table 1). The patient and control groups received rosuvastatin treatment upon CAE diagnosis, not oral statin therapy before the time of enrollment.

The primary endpoint included confirming the presence of inflammatory markers such as hs-CRP and IL- 6 after 6 months of treatment. The secondary endpoint included measuring hs-CRP and IL-6 levels and observing any side effects of rosuvastatin. According to the results of coronary angiography and patients' ages, participants were divided into four groups: CAE-A (age $\leq 50$ years), CAE-B (50 years <age $\leq 70$ years), CAE-C (age $>70$ years), and $\mathrm{NC}$ (age-matched) with normal coronary arteries. According to the 1:1 age-matching, other risk factors (such as sex, hypertension, and diabetes) were matched for as much as possible, except for the CAE status. This study was approved by the medical ethics committee of the Shanghai East Hospital, Shanghai East Hospital (Ji'an Campus), and Baoshan People's Hospital of the Yunnan Province.

\section{Measurement of related indicator characteristics}

Hypertension was defined as a systolic blood pressure (SBP) $\geq 140 \mathrm{mmHg}$ and/or diastolic blood pressure (DBP) $\geq 90 \mathrm{mmHg}$ [18]; BP was measured three times on the same day for patients not taking antihypertensive drugs. The smoking index was calculated as the number of cigarettes smoked per day $x$ the number of years of 


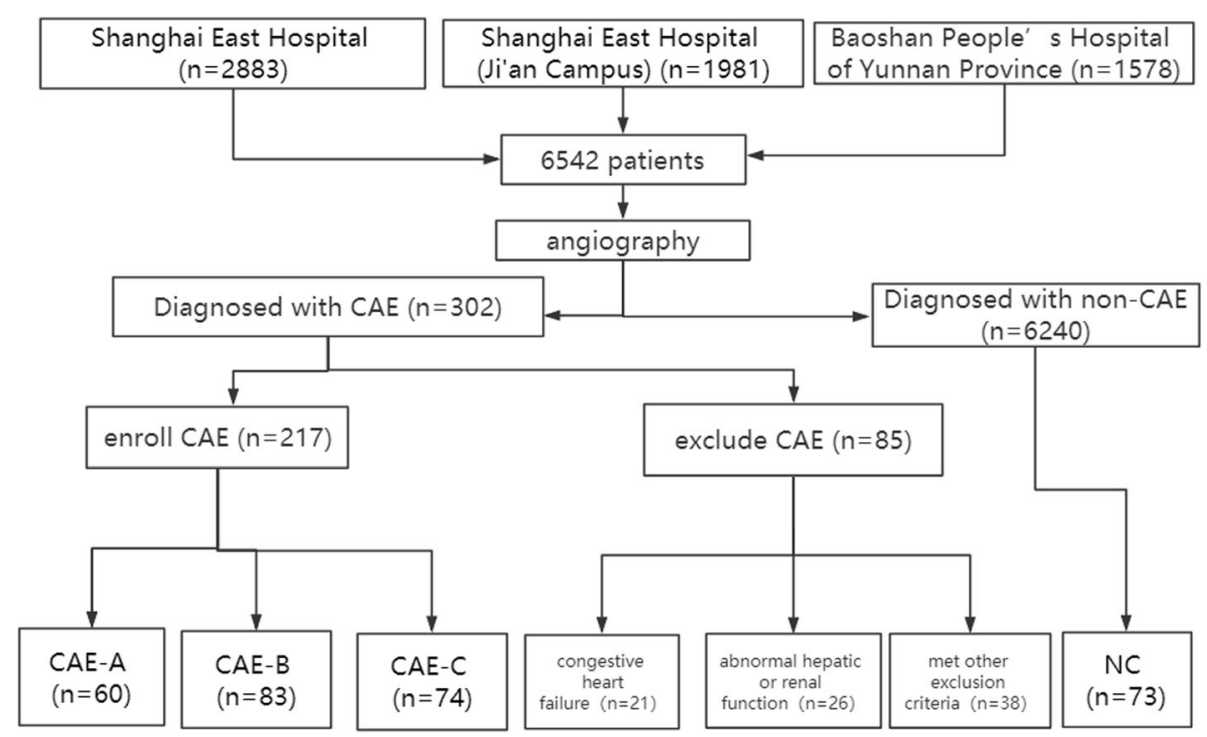

Fig. 1 The patient screening flow chart

smoking [19]. Fasting venous blood samples of all subjects were collected to measure hematological parameters and biochemical indices. The red blood cell distribution width, hemoglobin level, mean platelet volume, and white blood cell (WBC) counts were analyzed using a Horiba ABX 80 Diagnostics (ABX pentra Montpellier, France). Serum glucose and creatinine, HDL-C, LDL-C, total cholesterol (TC), triglycerides (TGs), hsCRP, and interleukin-6 (IL-6) levels were detected with enzymatic colorimetric methods using a fully automatic biochemical analyzer (Roche Cobas c702) in Shanghai East Hospital, Shanghai East Hospital (Ji'an Campus), and Baoshan People's Hospital of the Yunnan Province.

\section{Coronary angiography}

The Siemens Artis zeego III was used to conduct coronary angiography with a routine radial artery approach. $\mathrm{X}$-ray photography was performed with the injection of a contrast agent. Blood vessel diameter measurements were performed by skilled coronary intervention doctors. CAE was defined as local or diffuse dilated coronary arteries with diameters exceeding 1.5 fold that of the adjacent normal coronary lumen [20]. The coronary artery images considered indicative of CAE after qualitative comparative analysis by two independent operators were included in this study. Representative CAE images of the left circumflex branch (LCX) and right coronary artery (RCA) are shown (Fig. 2). Pharmacological therapy was withheld for at least $24 \mathrm{~h}$ before angiography.

\section{Statistical analysis}

Statistical analysis was conducted using SPSS software version 19.0. Continuous variables are presented as means \pm standard deviations for normally distributed data, while non-normally distributed data are presented as medians. Comparisons between two groups were conducted using an independent samples $t$-test and qualitative data were evaluated by Fisher's exact test. A comparison of continuous variables between the three groups was performed using the one-way ANOVA with post hoc Dunnett's correction. A $p$-value $<0.05$ was considered statistically significant. Logistic regression analysis and stepwise methods were applied to screen the factors showing correlations with CAE, with the entry criterion set at $p<0.05$ and the rejection criterion at $p>0.05$.

\section{Results}

From the study cohort, 302 patients were diagnosed with CAE, of which 85 were excluded based on the exclusion criteria. In addition, 73 patients were used as control group (NC group). The prevalence of CAE among all patients who underwent angiography in this study was $302 / 6542=0.046$, representing a $4.6 \%$ prevalence among all patients undergoing angiography.

Baseline characteristics of risk factors for CAE, including sex (male), hypertension, diabetes, hyperlipidemia, and smoking history, were similar in the total CAE and NC groups (Table 1). Particularly, the WBC counts were not significantly different between the groups. In addition, subclasses of leukocytes, such as neutrophils and lymphocytes, were not significantly different between the groups.

Laboratory findings such as TC, LDL-C, hs-CRP, and IL-6 were significantly higher in the total CAE group than in the NC group $(p<0.05)$. TC, LDL-C, hs-CRP, and IL-6 levels were significantly higher in the CAE-A 
Table 1 Basic information and laboratory findings of CAE patients and normal controls

\begin{tabular}{|c|c|c|c|c|c|c|c|c|c|}
\hline Groups & $\begin{array}{l}\text { NC group } \\
(n=73)\end{array}$ & $\begin{array}{l}\text { CAE-A }(n=60) \\
\text { (age } \leq 50 \\
\text { years) }\end{array}$ & $\begin{array}{l}\text { CAE-B }(n=83)(50 \\
\text { years<age } \leq 70 \\
\text { years })\end{array}$ & $\begin{array}{l}\text { CAE-C }(n=74) \\
\text { (age }>70 \\
\text { years) }\end{array}$ & $\begin{array}{l}\text { Total CAE } \\
(A+B+C \\
n=217)\end{array}$ & $\begin{array}{l}p- \\
\text { value }\end{array}$ & $\begin{array}{l}\text { CAE-A } \\
\text { vs CAE- } \\
\text { B }\end{array}$ & $\begin{array}{l}\text { CAE-B } \\
\text { vs CAE- } \\
\text { C }\end{array}$ & $\begin{array}{l}\text { CAE-A } \\
\text { vs CAE- } \\
\text { C }\end{array}$ \\
\hline Sex (M), n (\%) & $42(57.5)$ & $39(65.0)$ & $57(68.7)$ & $50(67.6)$ & $146(67.3)$ & 0.2794 & & & \\
\hline Diabetes mellitus, n (\%) & $13(17.8)$ & $11(18.3)$ & 18 (21.6) & $18(24.3)$ & $47(21.7)$ & 0.1712 & & & \\
\hline Hypertension, n (\%) & $23(31.5)$ & $19(31.7)$ & $28(33.7)$ & $27(36.5)$ & $74(34.1)$ & 0.2142 & & & \\
\hline Waist circumference $(\mathrm{cm})$ & $90.3 \pm 14.8$ & $91.6 \pm 12.7$ & $92.7 \pm 16.1$ & $93.8 \pm 19.1$ & $92.8 \pm 16.2$ & 0.5277 & & & \\
\hline Creatinine $(\mathrm{mg} / \mathrm{dL})$ & $\begin{array}{l}70.34 \pm \\
11.6\end{array}$ & $67.6 \pm 12.7$ & $77.8 \pm 13.2$ & $87.8 \pm 14.8$ & $78.48 \pm 12.5$ & 0.2560 & & & \\
\hline Smoking index & $\begin{array}{l}119.2 \pm \\
15.5\end{array}$ & $110.3 \pm 10.5$ & $135.5 \pm 15.6$ & $130.2 \pm 15.1$ & $126.7 \pm 17.8$ & 0.2391 & & & \\
\hline Total cholesterol (mmol/L) & $4.89 \pm 1.04$ & $5.59 \pm 1.21^{*}$ & $5.39 \pm 1.18$ & $4.95 \pm 1.07$ & $5.30 \pm 1.16^{*}$ & 0.0452 & 0.321 & 0.252 & 0.175 \\
\hline $\begin{array}{l}\text { Low-density lipoprotein-C } \\
(\mathrm{mmol} / \mathrm{L})\end{array}$ & $2.89 \pm 0.36$ & $3.92 \pm 0.54^{*}$ & $3.74 \pm 0.51^{*}$ & $3.73 \pm 0.49^{*}$ & $3.79 \pm 0.52^{*}$ & 0.0237 & 0.434 & 0.523 & 0.259 \\
\hline $\begin{array}{l}\text { High-density lipoprotein-C } \\
\text { (mmol/L) }\end{array}$ & $1.08 \pm 0.12$ & $1.22 \pm 0.27$ & $1.15 \pm 0.19$ & $1.13 \pm 0.15$ & $1.16 \pm 0.16$ & 0.9161 & & & \\
\hline Triglycerides (mmol/L) & $1.56 \pm 0.19$ & $1.69 \pm 0.19$ & $1.89 \pm 0.21$ & $1.75 \pm 0.18$ & $1.78 \pm 0.15$ & 0.8493 & & & \\
\hline High-sensitivity CRP (mg/L) & $16.9 \pm 3.82$ & $32.3 \pm 5.51^{*}$ & $26.1 \pm 4.23^{*}$ & $22.5 \pm 4.82^{*}$ & $25.6 \pm 4.65^{*}$ & 0.0213 & 0.230 & 0.198 & $0.048^{*}$ \\
\hline Glycated hemoglobin (\%) & $5.89 \pm 1.12$ & $5.90 \pm 1.07$ & $6.50 \pm 1.12$ & $6.89 \pm 1.25$ & $6.46 \pm 1.21$ & 0.1421 & & & \\
\hline Ejection fraction (\%) & $\begin{array}{l}56.3 \pm \\
12.58\end{array}$ & $59.4 \pm 9.14$ & $55.5 \pm 9.23$ & $50.3 \pm 8.47$ & $54.8 \pm 8.53$ & 0.3432 & & & \\
\hline Hemoglobin (g/L) & $\begin{array}{l}125.5 \pm \\
26.5\end{array}$ & $131.1 \pm 28.6$ & $125.1 \pm 26.3$ & $119.1 \pm 29.8$ & $123.8 \pm 28.1$ & 0.6535 & & & \\
\hline $\begin{array}{l}\text { Red blood cell distribution } \\
\text { width (\%) }\end{array}$ & $36.8 \pm 5.26$ & $36.7 \pm 5.95$ & $38.7 \pm 4.94$ & $36.4 \pm 4.68$ & $37.4 \pm 5.59$ & 0.8601 & & & \\
\hline Mean platelet volume (fL) & $10.5 \pm 1.26$ & $10.7 \pm 1.05$ & $11.2 \pm 1.35$ & $10.5 \pm 1.91$ & $10.8 \pm 1.45$ & 0.2503 & & & \\
\hline WBC $\left(10^{9} / \mathrm{L}\right)$ & $6.25 \pm 2.56$ & $8.85 \pm 2.21$ & $8.35 \pm 2.06$ & $8.25 \pm 2.36$ & $8.38 \pm 2.30$ & 0.0763 & & & \\
\hline Neutrophils $\left(10^{9} / \mathrm{L}\right)$ & $4.12 \pm 1.69$ & $6.12 \pm 1.58$ & $5.76 \pm 1.49$ & $5.66 \pm 1.52$ & $5.89 \pm 1.60$ & 0.0752 & & & \\
\hline Lymphocytes $\left(10^{9} / \mathrm{L}\right)$ & $0.50 \pm 0.22$ & $0.65 \pm 0.25$ & $0.68 \pm 0.23$ & $0.72 \pm 0.20$ & $0.70 \pm 0.23$ & 0.3854 & & & \\
\hline Neutrophils/Lymphocytes ratio & $8.18 \pm 5.36$ & $9.42 \pm 6.89$ & $8.48 \pm 6.56$ & $7.87 \pm 6.36$ & $8.41 \pm 6.60$ & 0.1025 & & & \\
\hline Interleukin-6 (pg/dL) & $4.1 \pm 0.6$ & $12.3 \pm 1.5^{*}$ & $10.9 \pm 1.3^{*}$ & $8.9 \pm 1.1^{*}$ & $10.6 \pm 1.3^{*}$ & 0.001 & 0.120 & 0.095 & $0.025^{*}$ \\
\hline
\end{tabular}

*:NC group vs. Total CAE group. $p$-value is considered significant if $<0.05$

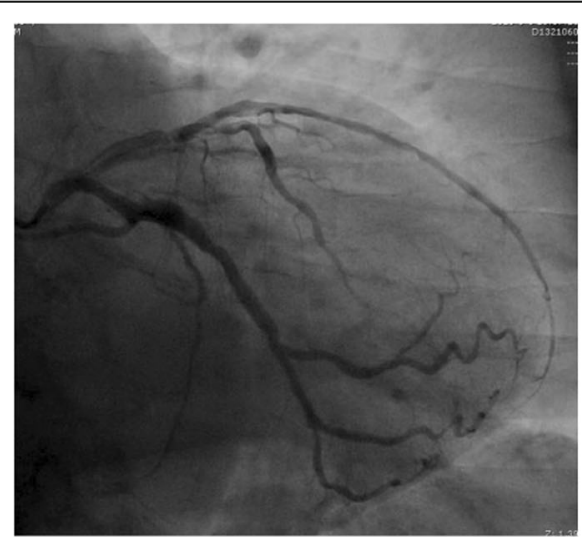

LCX

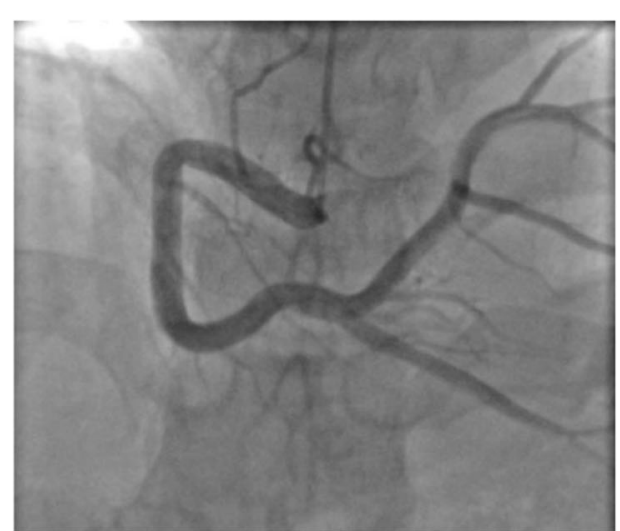

RCA

Fig. 2 Representative coronary artery ectasia images of left circumflex branch (LCX) and right coronary artery (RCA) 
group than in the CAE-B, CAE-C, and $\mathrm{NC}$ groups; furthermore, TC, LDL-C, hs-CRP, and IL-6 levels were significantly higher in the CAE-B group than in the CAE-C or NC group. Under similar circumstances, TC, LDL-C, hs-CRP, and IL-6 levels were significantly higher in the CAE-C group than in the NC group. There were significant differences in hs-CRP $(P=0.048)$ and IL-6 $(P=$ $0.025)$ levels but not in TC $(P=0.175)$ and LDL-C $(P=$ $0.259)$ levels between the CAE-A and CAE-C groups. There were no significant differences in sex, hypertension, diabetes, waist circumference, smoking index, TGs, glycosylated hemoglobin, red blood cell distribution width $(\mathrm{RBW})$, or mean platelet volume among the three different age groups of CAE patients ( $p>0.05$; Table 1$)$.

Logistic regression analysis was performed to identify independent risk factors associated with CAE. In the stepwise analysis, covariant factors included hypertension, diabetes mellitus, hs-CRP, LDL-C, smoking, triglycerides, WBC, and IL-6. Multivariate analysis showed that increased hs-CRP and IL-6 levels were independent predictors of CAE (Table 2), whereas multivariate analysis revealed only increased hs-CRP (OR, 1.782; CI, 1.1242.014; $p=0.021)$ and IL-6 (OR, 1.584; CI, 1.112-1.986; $p=0.030$ ) levels as independent predictors (Table 2). Baseline drug treatments of patients with confirmed diagnoses of CAE at study inclusion are shown in Table 3. No significant differences were observed in the baseline medication among the CAE groups (Table 3). There were no significant differences in the selection of therapeutic medications between the three CAE groups and the NC group $(p>0.05)$. As far as compliance issues are concerned, we were dedicated to ensure regular health education and regular outpatient follow-up visits. We also kept reminding patients to take medication by telephone, WeChat, and other means. For various reasons such as financial constraints, some patients could not access drugs.

Table 2 Multivariate analysis of variables associated with CAE

\begin{tabular}{llll}
\hline & OR & $95 \%$ Cl & $p$-value \\
\hline Hypertension & 1.364 & $0.932-1.648$ & 0.248 \\
Diabetes mellitus & 1.407 & $0.802-2.053$ & 0.198 \\
Waist circumference & 1.448 & $0.967-1.938$ & 0.124 \\
Total Cholesterol & 1.462 & $0.970-1.965$ & 0.112 \\
LDL-C & 1.492 & $0.986-2.091$ & 0.099 \\
Smoking & 1.119 & $0.932-1.422$ & 0.176 \\
TGs & 1.238 & $0.836-1.865$ & 0.236 \\
WBC & 1.690 & $0.990-1.785$ & 0.061 \\
hs-CRP & 1.782 & $1.124-2.014$ & $0.021^{*}$ \\
Interleukin-6 & 1.584 & $1.112-1.986$ & $0.030^{*}$ \\
\hline CAE cornary ary
\end{tabular}

$C A E$ coronary artery ectasia, $h s-C R P$ high-sensitivity C-reactive protein, $L D L-C$ low-density lipoprotein cholesterol, TGs triglycerides, WBC white blood cells. *: $p<0.05$ vs NC group OR, odds ratio and $\mathrm{Cl}$, confidence interval
After the 6-month treatment with rosuvastatin, serum hs-CRP and IL- 6 levels were reduced in the three CAE age groups (Table 4), supporting the efficacy of rosuvastatin as an anti-inflammatory agent. Of the three CAE age groups, the CAE-A (age $\leq 50$ years) group showed the greatest effect of rosuvastatin treatment, as evidenced by the most significant reduction in serum hs-CRP (delta value was $15.1 \pm 3.33, P=0.0001$ ) and IL-6 (delta value was $5.9 \pm 1.6, P=0.021$ ) levels. This group showed the greatest reduction in serum hs-CRP and IL-6 levels, followed by the CAE-B group (delta value of hs-CRP was $9.4 \pm 2.86, P=0.023$, delta value of IL-6 was $3.0 \pm 1.5, P=$ 0.043). The results of the follow-up found that younger patients had a greater reduction in serum hs-CRP and IL6 levels, suggesting that rosuvastatin had a greater antiinflammatory effect in younger patients (Table 4).

\section{Discussion}

Dyslipidemia is a well-recognized, major risk factor for atherosclerosis [21, 22]. Increased serum lipids, especially LDL-C, can deposit in the arterial wall and gradually form atherosclerotic plaques, which can consequently block the native artery and cause cardiovascular diseases, such as coronary heart disease [23]. Increased inflammation is the core process in all stages of atherosclerosis. With the application and development of several techniques such as anti-inflammatory therapy, antithrombotics, thrombolysis drugs, and catheter treatment in recent decades, the incidence and mortality due to atherosclerosis or obstructive vascular diseases have been significantly reduced $[24,25]$. CAE is a multifactorial disease, and its pathogenic mechanism has not yet been fully elucidated. CAE is considered a variation of atherosclerosis, mainly resulting from the thinning and/ or destruction of the myocardial membrane. However, the dilatation process may be independent of the atherosclerotic process because it can be found as an isolated lesion in the coronary arteries and other vascular systems [26]. Dahhan A argued that atherosclerotic CAE does not carry additional risks compared to atherosclerotic coronary artery disease without ectasia [27]. Aksu T, Uygur B, Kosar, suggested that risk factors for CAD and the clinical presentation of CAE were considerably similar, and this situation was consistent with the similar etiopathogenesis of the two diseases [28]. Elevated inflammatory markers, such as plasma IL- 6 and plasma soluble adhesion molecules, are closely linked to the presence of coronary artery dilation [29-31]. One study has indicated increasing evidence that neutrophils and neutrophil-derived products participate in atherogenesis and CAE [32]. The neutrophil/lymphocyte ratio was higher in patients with CAD, coronary slow flow, and CAE than in those with a normal coronary anatomy. The NLR may be an indicator of CAD, CAE, and 
Table 3 Baseline medication selection of CAE patients after confirmed diagnosis

\begin{tabular}{|c|c|c|c|c|c|c|}
\hline Treatments & $\begin{array}{l}\text { Group NC } \\
(n=73)\end{array}$ & $\begin{array}{l}\text { CAE-A }(n=60) \text { (age } \leq \\
50 \text { years) }\end{array}$ & $\begin{array}{l}\text { CAE-B }(n=83)(50 \text { years }< \\
\text { age } \leq 70 \text { years })\end{array}$ & $\begin{array}{l}\text { CAE-C }(n=74) \text { (age }> \\
70 \text { years) }\end{array}$ & $\begin{array}{l}\text { Total CAE }(A+B+C, \\
n=217)\end{array}$ & $\begin{array}{l}p- \\
\text { value } \\
\end{array}$ \\
\hline ACEI/ARB & 18 & 16 & 27 & 28 & 71 & 0.895 \\
\hline$\beta$-receptor blocker & 21 & 25 & 36 & 28 & 89 & 0.424 \\
\hline Rosuvastatin & 73 & 60 & 83 & 74 & 217 & 0.945 \\
\hline $\begin{array}{l}\text { Calcium-channel } \\
\text { blocker }\end{array}$ & 16 & 18 & 15 & 17 & 50 & 0.310 \\
\hline Diuretics & 14 & 15 & 13 & 16 & 44 & 0.769 \\
\hline Aspirin & 35 & 42 & 56 & 50 & 148 & 0.424 \\
\hline
\end{tabular}

$p$-value: total CAE vs NC. CAE coronary artery ectasia, $A C E$ angiotensin-converting enzyme

coronary slow flow. This finding suggests that a more severe inflammatory process could be involved in CAE development [33-35]. In our study, we also studied the NLR between the NC and total CAE groups; the NLR was higher in the total CAE group than in the $\mathrm{NC}$ group, indicating the tendency of severe inflammation in CAE, although the result was not statistically significant $(P=0.1025)$. A more significant level of chronic inflammation might be linked with CAE pathogenesis, which is associated with both inflammatory markers and inflammatory cells in CAE patients [36].

Long-term exposure to nitrites, herbicide sprays, acetylcholine inhibitors, cocaine, and smoking can also lead to degeneration of the endothelium of the coronary arteries through oxidative stress-induced inflammation, which can eventually cause CAE [12]. Research on inflammation and CAE has characterized CAE-related inflammation, which includes elevated hs-CRP and IL-6 levels [37]. Accumulation of excess circulating LDL-C was associated with an overproduction of reactive oxygen species and increase in proinflammatory cytokines in the coronary endothelium, linking elevated cholesterol with cardiovascular inflammation [38].

Limited studies have focused on the inflammatory status of different age groups of CAE patients. TC and LDL-C levels are important for risk evaluation of coronary heart disease, which benefits from statin therapy through the reduction in LDL-C, hs-CRP, and IL-6 levels [39]. We hypothesized that increased inflammatory marker levels observed in younger patients (CAE-A) can be explained by several factors. First, younger patients are more likely to be stressed, resulting in a more primed or activated inflammatory status [40]. In addition, younger patients responded more strongly to physical and emotional stimulation, which can lead to increased inflammatory marker levels. There are other lifestyle factors that can also lead to inflammation, such as cocaine abuse and trauma [41].

Previous prospective studies have also found that statins can efficiently slow down the growth rate of an abdominal aortic aneurysm compared with the growth rate of abdominal aortic aneurysms in controls [42]. In the present study, the efficacy of rosuvastatin in CAE patients in different age groups was investigated and compared. The findings may be explained by higher inflammatory marker levels in younger patients than in older patients; thus, the same dose of rosuvastatin could be more likely to produce a greater anti-inflammatory effect. Moreover, a smaller percentage of younger people had never taken rosuvastatin before. Older patients had a higher proportion of rosuvastatin history because of arteriosclerosis, hyperlipidemia, and stroke, among other health complications. Therefore, the lipid-lowering effect of rosuvastatin may be more potent, which boosts its anti-inflammatory effects in young patients. The Cholesterol Treatment Trialists' Collaboration reported that the efficacy of statin therapy was lower in older patients than in younger patients [43]. Furthermore, younger individuals have a higher basal metabolism level with regard to lipid synthesis and degradation [44]; therefore, younger CAE patients could be more sensitive to rosuvastatin treatment. After rosuvastatin treatment, hs-CRP and IL-6 levels of the CAE-A group were reduced to levels comparable to those of the NC group, while those of the CAE-C group were only partially reversed, indicating that the inflammatory status of younger CAE patients was more severe but reversible, while that of older CAE patients was comparatively mild, persistent, and irreversible.

\section{Study limitations}

First, this study was based on a relatively small number of patients, although a large sample size was examined. Second, although specific exclusion criteria were chosen, some confounding factors may still have caused interference, for example, the accurate assessment of coronary artery diameter may have been limited due to uncertainty in identifying the reference parts of the vessel. It would have been better to use intravascular ultrasound or optical coherence tomography to provide more accurate information about the vessel. Third, pharmacological therapy was withheld for at least $24 \mathrm{~h}$ before cardiac catheterization, but this period may not have been a long 


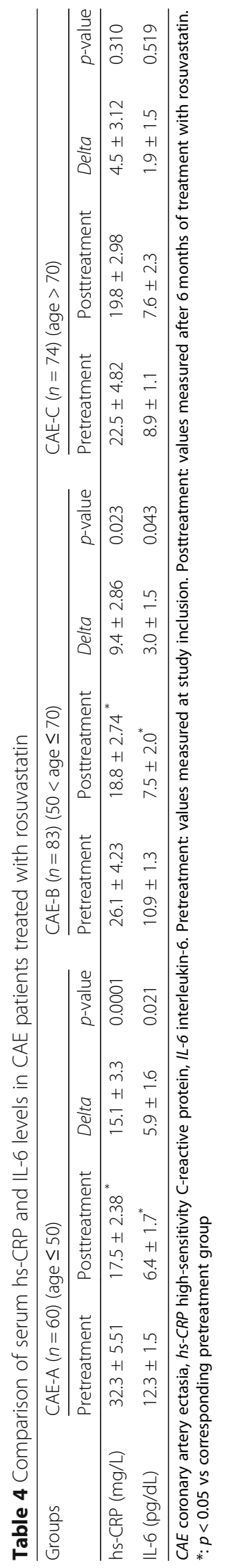


enough washout period to exclude possible effects of drugs on the plasma inflammatory markers.

\section{Conclusions}

Younger CAE patients had higher inflammatory marker levels than older CAE patients. The greatest efficacy of anti-inflammatory treatment was found in younger CAE patients, suggesting that rosuvastatin should be prescribed at the time of CAE diagnosis, especially in younger patients.

\section{Abbreviations}

ACEls: Angiotensin-converting enzyme inhibitors; ARBs: Angiotensin-receptor blocker; CAE: Coronary artery ectasia; hs-CRP: High-sensitivity C-reactive protein; IL-6: Interleukin-6; LDL-C: Low-density lipoprotein cholesterol; PO: Per os; QN: Quaque nocte; WBC: White blood cell

\section{Acknowledgments}

Not applicable.

\section{Authors' contributions}

CHF and YH contributed equally to this work. CHF acquired, analyzed, and interpreted the data; and wrote the manuscript. YH acquired, analyzed, and interpreted the data; and revised the manuscript. RLL designed the study and acquired, analyzed, and interpreted the data. LY revised the manuscript; and $\mathrm{XLL}, \mathrm{YHL}$, and $\mathrm{ZHH}$ acquired the data. All authors read and approved the final manuscript.

\section{Funding}

This work was supported by the China National Natural Science Foundation Grant (81801379); Top-level Clinical Discipline Project of the Shanghai Pudong District Grant (PWYgf2018-02); the Shanghai Municipal Health and Planning Commission Grant (201840112); and the Program for Young Excellent Talents in Tongji University, Fundamental Research Funds for the Central Universities (22120180600)

\section{Availability of data and materials}

Study protocol and data set: Not available. Statistical code: Available from Dr. Luo (e-mail, luoyu201909@163.com).

\section{Ethics approval and consent to participate}

The ethics committee of the Shanghai East Hospital, Shanghai East Hospital (Ji'an Campus), and Cardiovascular Medicine of Baoshan People's Hospital of the Yunnan Province approved the study, and all patients provided written informed consent prior to participating in the study.

\section{Consent for publication}

Not applicable.

\section{Competing interests}

The authors declare that they have no competing interests.

\section{Author details}

${ }^{1}$ Department of Cardiology, Shanghai East Hospital, Tongji University, 1800 Yuntai Rd, Shanghai 200126, People's Republic of China. ${ }^{2}$ Cardiovascular Medicine of Baoshan People's Hospital of the Yunnan Province, Kunming Medical University, Baoshan 678000, People's Republic of China. ${ }^{3}$ Department of Cardiology, Shanghai East Hospital (Ji'an Campus), Medical School, Jinggangshan University, Ji'an 343009, People's Republic of China.

Received: 4 April 2020 Accepted: 26 June 2020

Published online: 11 July 2020

\section{References}

1. Hartnell GG, Parnell BM, Pridie RB. Coronary artery ectasia. Its prevalence and clinical significance in 4993 patients. Heart. 1985;54:392-5.
2. Carino D, Agarwal A, Singh M, Meadows J, Ziganshin BA, Elefteriades JA Coronary aneurysm: an enigma wrapped in a mystery. Aorta (Stamford) 2019;7:71-4

3. Tandon V, Tandon AA, Kumar M, Mosebach CM, Balakumaran K. Coronary artery aneurysms: analysis of comorbidities from the national inpatient sample. Cureus. 2019:11:e4876.

4. Ozturk S, Yetkin E, Waltenberger J. Molecular and cellular insights into the pathogenesis of coronary artery ectasia. Cardiovasc Pathol. 2018;35:37-47.

5. Kahraman F, Karabacak M, Türker $Y$. Serum nitric oxide level in patients with coronary artery ectasia. Anatol J Cardiol. 2017;17:341.

6. Sudhir K, Ports TA, Amidon TM, Goldberger JJ, Bhushan V, Kane JP, et al. Increased prevalence of coronary ectasia in heterozygous familial hypercholesterolemia. Circulation. 1995;91:1375-80.

7. James PA, Oparil S, Carter BL, Cushman WC, Dennison-Himmelfarb C, Handler J, et al. 2014 evidence-based guideline for the management of high blood pressure in adults: report from the panel members appointed to the eighth joint National Committee (JNC 8). JAMA. 2014;311:507-20.

8. Liu L, Huang C, Liao W, Chen S, Cai S. Smoking behavior and smoking index as prognostic indicators for patients with esophageal squamous cel carcinoma who underwent surgery: a large cohort study in Guangzhou, China. Tob Induc Dis. 2020;18:9.

9. Luo Y, Tang J, Liu X, Qiu J, Ye Z, Lai Y, et al. Coronary artery aneurysm differs from coronary artery ectasia: angiographic characteristics and cardiovascular risk factor analysis in patients referred for coronary angiography. Angiology. 2017;68:823-30.

10. Raffetto JD, Khalil RA. Matrix metalloproteinases and their inhibitors in vascular remodeling and vascular disease. Biochem Pharmacol. 2008;75:346-59.

11. Tun B, Frishman WH. Effects of anti-inflammatory medications in patients with coronary artery disease: a focus on Losmapimod. Cardiol Rev. 2018; 26(3):152-6.

12. Seker FB, Kilic U, Caglayan B, Ethemoglu MS, Caglayan AB, Ekimci N, et al. HMG-CoA reductase inhibitor rosuvastatin improves abnormal brain electrical activity via mechanisms involving eNOS. Neuroscience. 2015;284:349-59.

13. Kim S, Kim CH, Vaziri ND. Upregulation of hepatic LDL receptor-related protein in nephrotic syndrome: response to statin therapy. Am J Physiol Endocrinol Metab. 2005:288:E813-7.

14. Tremoulet AH, Jain S, Jone P-N, Best BM, Duxbury EH, Franco A, et al. Phase V/lla trial of atorvastatin in patients with acute kawasaki disease with coronary artery aneurysm. J Pediatrics. 2019;215:107-17.e12.

15. Chen J, Li D, Schaefer R, Mehta JL. Cross-talk between dyslipidemia and renin-angiotensin system and the role of LOX-1 and MAPK in atherogenesis studies with the combined use of rosuvastatin and candesartan. Atherosclerosis. 2006;184:295-301.

16. Li Z, Wang L, Hu X, Zhang P, Chen Y, Liu X, et al. Effect of rosuvastatin on atherosclerotic plaque stability: an intravascular ultrasound elastography study. Atherosclerosis. 2016;248:27-35.

17. Dendramis G, Paleologo C, Piraino D, Assennato P. Relationship between coronary artery ectasia, cocaine abuse and acute coronary syndromes. World J Cardiol. 2016:8:351-5.

18. Rashid S, Gul U, Ali M, Sadiq T, Mehmood KA. Coronary artery ectasia: clinical and angiographic features. J Coll Physicians Surg Pak. 2018;28:824-8.

19. Gamboa CM, Safford MM, Levitan EB, Mann DM, Yun H, Glasser SP, et al. Statin underuse and low prevalence of LDL-C control among U.S. adults at high risk of coronary heart disease. Am J Med Sci. 2014;348:108-14.

20. CASS Principal Investigators and their Associates. Coronary Artery Surgery Study (CASS): a randomized trial of coronary artery bypass surgery: survival data. 1983:68(5):939-50.

21. Petrie JR, Guzik TJ, Touyz RM. Diabetes, hypertension, and cardiovascular disease: clinical insights and vascular mechanisms. Can J Cardiol. 2018:34: $575-84$

22. van Rooy M-J, Pretorius E. Obesity, hypertension and hypercholesterolemia as risk factors for atherosclerosis leading to ischemic events. Curr Med Chem. 2014;21:2121-9.

23. Uygun T, Demir B, Tosun V, Ungan I, Kural A, Çiftçi R, et al. Relationship between interleukin-17A and isolated coronary ectasia. Cytokine. 2019;115:84-8.

24. Iwańczyk S, Borger M, Kamiński M, Chmara E, Cieślewicz A, Tykarski A, et al. Inflammatory response in patients with coronary artery ectasia and coronary artery disease. Kardiol Pol. 2019:77:713-5.

25. Monte S, Macchia A, Pellegrini F, Romero M, Lepore V, D'Ettorre A, et al. Antithrombotic treatment is strongly underused despite reducing overall 
mortality among high-risk elderly patients hospitalized with atrial fibrillation. Eur Heart J. 2006;27:2217-23.

26. Tomioka T, Takeuchi S, Ito Y, Shioiri H, Koyama J, Inoue K. Recurrent acute myocardial infarction in a patient with severe coronary artery ectasia: implication of antithrombotic therapy. Am J Case Rep. 2016;17:939-43.

27. Dahhan A. Coronary artery ectasia in atherosclerotic coronary artery disease, inflammatory disorders, and sickle cell disease. Cardiovasc Ther. 2015;33:7988. https://doi.org/10.1111/1755-5922.12106.

28. Aksu T, Uygur B, Kosar MD, Guray U, Arat N, Korkmaz S, Colak A. Coronary artery ectasia: its frequency and relationship with atherosclerotic risk factors in patients undergoing cardiac catheterization. Anadolu Kardiyol Dergisi/ Anatol J Cardiol. 2011;11:280-5. https://doi.org/10.5152/akd.2011.076.

29. Brunetti ND, Salvemini G, Cuculo A, Ruggiero A, De Gennaro L, Gaglione A, et al. Coronary artery ectasia is related to coronary slow flow and inflammatory activation. Atherosclerosis. 2014;233:636-40

30. Tokgozoglu L, Ergene O, Kinay O, Nazli C, Hascelik G, Hoscan Y. Plasma interleukin-6 levels are increased in coronary artery ectasia. Acta Cardiol. 2004;59:515-9.

31. Pranata R, Yonas E, Chintya V, Alkatiri AA. Is anticoagulant necessary in patients with coronary artery ectasia presenting with acute coronary syndrome? A systematic review of case reports. Int J Angiol. 2019;28:231-6.

32. Guo Y, Liu R, Chen L, Wu W, Zhang S. Neutrophil activation and neutrophi derived neutrophil extracellular trap formation in patients with coronary artery ectasia. BMC Cardiovasc Disord. 2020;20:101.

33. Yılmaz M, Korkmaz H, Bilen MN, Uku Ö, Kurtoğlu E. Could neutrophil/ lymphocyte ratio be an indicator of coronary artery disease, coronary artery ectasia and coronary slow flow? J Int Med Res. 2016;44:1443-53.

34. Kalaycıoğlu E, Gökdeniz T, Aykan AC, et al. Comparison of neutrophil to lymphocyte ratio in patients with coronary artery ectasia versus patients with obstructive coronary artery disease. Kardiol Pol. 2014;72(4):372-80. https://doi.org/10.5603/KP.a2013.0349

35. Balta S, Demirkol S, Celik T, Kucuk U, Unlu M, Arslan Z, et al. Association between coronary artery ectasia and neutrophil-lymphocyte ratio. Angiology. 2013;64:627-32.

36. Li JJ, Nie SP, Qian XW, Zeng HS, Zhang CY. Chronic inflammatory status in patients with coronary artery ectasia. Cytokine. 2009;46:61-4.

37. Boles U, Wiklund U, David S, Ahmed K, Henein MY. Coronary artery ectasia carries worse prognosis: a long-term follow-up study. Pol Arch Intern Med. 2019:129:833-5.

38. Catapano AL, Pirillo A, Norata GD. Vascular inflammation and low-density lipoproteins: is cholesterol the link? A lesson from the clinical trials. Br J Pharmacol. 2017;174:3973-85.

39. Jafari J, Daum A, Hamed JA, Osherov A, Orlov Y, Yosefy C, et al. Low highdensity lipoprotein cholesterol predisposes to coronary artery ectasia. Biomedicines. 2019;7:E79.

40. Hwang SY. Comparison of clinical manifestations and treatment-seeking behavior in younger and older patients with first-time acute coronary syndrome. J Korean Acad Nurs. 2009:39:888-98.

41. Gregoratos G. Clinical manifestations of acute myocardial infarction in older patients. Am J Geriatr Cardiol. 2001;10:345-7.

42. Li Y, Lu G, Sun D, Zuo H, Wang DW, Yan J. Inhibition of endoplasmic reticulum stress signaling pathway: a new mechanism of statins to suppress the development of abdominal aortic aneurysm. PLoS One. 2017;12: e0174821.

43. Cholesterol Treatment Trialists' Collaboration. Efficacy and safety of statin therapy in older people: a meta-analysis of individual participant data from 28 randomised controlled trials. Lancet. 2019;393:407-15.

44. Thuresson M, Jarlöv MB, Lindahl B, Svensson L, Zedigh C, Herlitz J. Thoughts, actions, and factors associated with prehospital delay in patients with acute coronary syndrome. Heart Lung. 2007;36:398-409.

\section{Publisher's Note}

Springer Nature remains neutral with regard to jurisdictional claims in published maps and institutional affiliations.

Ready to submit your research? Choose BMC and benefit from:

- fast, convenient online submission

- thorough peer review by experienced researchers in your field

- rapid publication on acceptance

- support for research data, including large and complex data types

- gold Open Access which fosters wider collaboration and increased citations

- maximum visibility for your research: over $100 \mathrm{M}$ website views per year

At BMC, research is always in progress.

Learn more biomedcentral.com/submissions 